\title{
Aetiology and outcome of severe community-acquired pneumonia in Singapore
}

\author{
Y-K. Tan, K-L. Khoo, S-P. Chin, Y-Y. Ong
}

Aetiology and outcome of severe community-acquired pneumonia in Singapore. Y-K. Tan, K-L. Khoo, S-P. Chin, Y-Y. Ong. CERS Journals Ltd 1998.

ABSTRACT: The aim of this study was to determine the aetiology and outcome of severe community-acquired pneumonia, and to assess whether the existing guidelines for initial antimicrobial therapy are being applied.

The records of 57 consecutive nonimmunocompromised patients admitted to the medical intensive care unit (ICU) between January 1989 and May 1993 with this diagnosis were reviewed. The microbiological data, chest radiographic changes and outcome were analysed.

Nine $(16 \%)$ of the 57 patients had pulmonary tuberculosis. When these patients were excluded from further analysis, a microbiological diagnosis was made in 41 $(72 \%)$ cases. The most commonest pathogens were Burkholderia pseudomallei $(\mathrm{n}=10)$, Klebsiella spp. $(\mathrm{n}=5)$ and Staphylococcus aureus $(\mathrm{n}=5)$, Mycoplasma pneumoniae $(\mathrm{n}=4)$ and Streptococcus pneumoniae $(\mathrm{n}=2)$ were less common. This microbiological spectrum was quite different from that in the West, where the incidence of $S$. pneumoniae was higher. Also, when pulmonary tuberculosis was excluded, the mortality $(67 \%)$ was much higher than that in other series. This was attributed to the high incidence of unrecognized $B$. pseudomallei infection, which is associated with a very high mortality in the region under study.

In addition to applying published guidelines on severe community-acquired pneumonia, the endemicity of certain organisms such as Mycobacterium tuberculosis and Burkholderia pseudomallei in different geographical regions needs to be considered when choosing initial empirical antimicrobial therapy.

Eur Respir J 1998; 12: 113-115.
Dept of Respiratory and Critical Care Medicine, Singapore General Hospital, Singapore.

Correspondence: Y-K. Tan

Dept of Respiratory and Critical Care Medicine

Singapore General Hospital

Outram Road

Singapore 169608

Fax: 652271736

Keywords: Burkholderia pseudomallei endemicity

guidelines

initial empirical antimicrobial therapy outcome

severe community-acquired pneumonia

Received: September 21997

Accepted after revision March 91998
Severe community-acquired pneumonia (SCAP) occurs in approximately 18-36\% of all community-acquired pneumonia (CAP) [1-3] and is associated with a mortality of up to $58 \%$ [4]. This condition has considerable economical impact because of the need for intensive care monitoring and mechanical ventilation, the loss of productivity through prolonged hospitalization and the loss of life. The most common organisms responsible for SCAP in the West are Streptococcus pneumoniae, gram-negative bacilli and Legionella pneumophila. Haemophilus influenzae and Staphylococcus aureus are less common causes of SCAP $[4,5]$. Guidelines [6-8] now exist for the initial empirical management of SCAP, but there may be variation in the aetiological agents in different geographical areas and, therefore, provision for this variation may be necessary when treating patients in different geographical regions.

There is very little literature on the aetiology of SCAP in Asia [9, 10]. The present study aimed to look at whether there is a difference between the aetiological agents in SCAP in an Asian country and those in the West, where most published guidelines originate. If the aetiological agents in the Asian community were found to be different from those in the West, such information should be added to the recommendations for initial antimicrobial agents from the consensus of the American, British and Canadian Thoracic Societies.

\section{Subjects and methods}

This was a retrospective study of 57 consecutive patients admitted to the intensive care unit (ICU) of Singapore General Hospital from January 1989 to May 1993 with the diagnosis of SCAP. A diagnosis of CAP was made when there was an acute lower respiratory tract infection with an onset before admission to hospital, associated with clinical and radiological evidence of pulmonary consolidation within $48 \mathrm{~h}$ of admission. Patients $>12 \mathrm{yrs}$ of age and those without a history of recent hospitalization within a month were eligible. Patients were excluded if they had pulmonary oedema, aspiration pneumonia, underlying immunocompromised states, such as malignancy, organ transplantation, infection with the human immunodeficiency virus (HIV), underlying chronic obstructive pulmonary disease (COPD), bronchiectasis, or restrictive lung disease. Although COPD is a risk factor for CAP, not all such patients with SCAP were routinely admitted to the ICU because of limited resources, and they were thus excluded from the analysis. 
Patients who were admitted from chronic care facilities such as nursing homes were also excluded. ICU admissions were for mechanical ventilation, potential ventilatory support, or intensive medical and nursing care and monitoring.

The data recorded included age and sex, history of smoking, diabetes mellitus and alcohol misuse, chest radiographic changes, results of microbiological investigations, and outcome. The microbiological data were based primarily on sputum and/or endotracheal aspirate Gram-stain and culture, acid-fast bacilli smear and mycobacterial cultures, blood cultures, and serology for Mycoplasma and Legionella, taken within $24 \mathrm{~h}$ of admission to hospital. Pleural fluid cultures, bronchoscopy and bronchoalveolar lavage (BAL) were also performed if indicated.

A definitive diagnosis of the aetiological agent was made when either the blood cultures or the pleural fluid cultures were positive, or when the acid-fast bacilli smear or mycobacterial cultures in sputum were positive. A probable diagnosis of the aetiological agent was made when there was: 1) a four-fold rise in mycoplasma serology or a single titre of 1:128 in the presence of cold agglutinins; or 2) a four-fold rise in Legionella serology or a single titre of 1:256 or higher. A probable diagnosis was also made when sputum, endotracheal aspirate and BAL cultures were positive.

\section{Results}

A total of 57 patients were identified during the study period (table 1). Nine patients had active pulmonary tuberculosis based on acid-fast bacilli smear or mycobacterial cultures from sputum. After excluding these patients, 48 patients remained ( 35 males and 13 females) with SCAP. Their mean ( \pm SD) age was $53 \pm 18$ yrs (range $12-86$

Table 1. - Aetiological agents and outcome

\begin{tabular}{|c|c|c|}
\hline $\begin{array}{l}\text { Aetiological } \\
\text { agent }\end{array}$ & $\begin{array}{c}\text { No. of } \\
\text { patients } \\
(\%) \\
n=57\end{array}$ & $\begin{array}{c}\text { No. of patients } \\
\text { who died } \\
\text { (\% mortality) } \\
n=35\end{array}$ \\
\hline $\begin{array}{l}\text { Mycobacterium tuberculosis } \\
\text { (acid-fast bacilli smear) }\end{array}$ & $9(16)$ & $3(5)$ \\
\hline $\begin{array}{l}\text { Burkholderia pseudomallei } \\
\text { (nine from blood culture, one } \\
\text { from pleural fluid and sputum) }\end{array}$ & $10(18)$ & $10(18)$ \\
\hline $\begin{array}{l}\text { Klebsiella sp. } \\
\text { (four from blood, culture, one } \\
\text { from sputum and ETT culture) }\end{array}$ & $5(9)$ & $3(5)$ \\
\hline $\begin{array}{l}\text { Staphylococcus aureus } \\
\text { (four from blood culture, } \\
\text { one from BAL culture) }\end{array}$ & $5(9)$ & $3(5)$ \\
\hline $\begin{array}{l}\text { Mycoplasma pneumoniae } \\
\text { (four from serology) }\end{array}$ & $4(7)$ & $0(0)$ \\
\hline $\begin{array}{l}\text { Streptococcus pneumoniae } \\
\text { (three from blood culture, } \\
\text { one from BAL culture) }\end{array}$ & $4(7)$ & $2(4)$ \\
\hline $\begin{array}{l}\text { Legionella pneumophila } \\
\text { (two from serology) }\end{array}$ & $2(4)$ & $1(2)$ \\
\hline $\begin{array}{l}\text { Pseudomonas aeruginosa } \\
\text { (one from ETT culture, one } \\
\text { from sputum and BAL culture) }\end{array}$ & $2(4)$ & $0(0)$ \\
\hline $\begin{array}{l}\text { Escherichia coli } \\
\text { (one from blood culture) }\end{array}$ & $1(2)$ & $1(2)$ \\
\hline Unknown & $15(26)$ & $12(21)$ \\
\hline
\end{tabular}

ETT: endotracheal tube; BAL: bronchoalveolar lavage. yrs). All but two required mechanical ventilation and their mean length of stay in the ICU was $9.1 \pm 9.0$ days. Twenty $(42 \%)$ were present smokers of exsmokers, 14 (29\%) had diabetes mellitus and six (12\%) had a history of alcohol misuse.

After excluding pulmonary tuberculosis, the top three causative pathogens in this series were $B$. pseudomallei $(\mathrm{n}=10)$, S. aureus $(\mathrm{n}=4)$ and Klebsiella spp. $(\mathrm{n}=4)$. Five of the patients with $B$. pseudomallei infection $(50 \%)$ had diabetes mellitus and one had a history of alcohol misuse. The overall mortality was $61 \%$. If pulmonary tuberculosis was excluded, the mortality was $67 \%$.

\section{Discussion}

In this study of patients with SCAP admitted to the ICU, 9 patients had pneumonia due to $M$. tuberculosis. Although rare in the West, this agent has also been reported in a few other Asian countries [9, 10]. This aetiological agent should thus still be considered in patients presenting with CAP in countries where tuberculosis is endemic. Ten patients had pneumonia due to B. pseudomallei. This infection is endemic in many south-east Asian countries [11, 12] and northern Australia [13]. This organism was found by another centre in Singapore to cause $7 \%$ of SCAP cases [10]. All patients who had this infection died. The antibiotics of choice are a combination of intravenous ceftazidime and oral doxycline [14]. Regarding the remaining pathogens, the numbers were too small to make any significant conclusion.

The present series showed that the aetiological agent could be identified in a large percentage of patients (74\%). This was because a large number of patients with SCAP were bacteraemic and it emphasizes the need for routine blood cultures in patients with SCAP. Some prospective studies have made no aetiological diagnosis in $31-61 \%$ of patients $[15,16]$.

The mortality of patients with SCAP was much higher in the present series than in other studies and was as high as the mortality (63\%) in another centre in Singapore [10]. This was attributed to the very high mortality associated with unsuspected B. pseudomallei infection.

The findings in the present series were further strengthened by similar findings in another retrospective study by a different centre in Singapore [10]. In addition to the recommendations by the American, Canadian and British Thoracic Societies, the endemicity of certain organisms in different geographical region needs to be considered. For instance, in south-east Asian countries and northern Australia, it is important to target initial empirical antimicrobials for severe community-acquired pneumonia against B. pseudomallei. Anstey et al. [17] found that a fatal outcome was strongly associated with inappropriate initial antibiotic therapy and identified appropriately tailored therapeutic regimens for the Northern Territory of Australia. A useful antibiotic regimen for patients with severe-community-acquired pneumonia in Singapore would be a combination of intravenous ceftazidime (high dose), cloxacillin and oral doxycycline. This combination of antimicrobials would cover the more usual pathogens in severe community-acquired pneumonia, Staphylococcus aureus, atypical pneumonia (Mycoplasma pneumonia, Legionella pneumophila and Chlamydia spp.) and Burkholderia pseudomallei. 


\section{References}

1. Marrie TJ, Durant H, Yates L. Community-acquired pneumonia requiring hospitalisation: 5-year prospective study. Rev Infect Dis 1989; 11: 586-599.

2. Sorensen J, Forsberg P, Hakanson E, et al. A new diagnostic approach to the patient with severe pneumonia. Scand J Infect Dis 1989; 21: 33-41.

3. Woodhead MA, Macfarlane JT, Rodgers FG, Laverick A, Pilkington R, Macrae AD. Aetiology and outcome of severe community-acquired pneumonia. J Infect 1985; 10: 204-210.

4. Hirani NA, Macfarlane JT. Impact of management guidelines on the outcome of severe community acquired pneumonia. Thorax 1997; 52: 17-21.

5. Moire P, Verchen JB, Chevret S, Chastang C, Gajdos P. Severe community-acquired pneumonia: etiology, epidemiology, and prognosis factors. Chest 1994; 105: 1487-1495.

6. Niederman MS, Bass JB, Campbell GD, et al. Guidelines for the initial management of adults with communityacquired pneumonia: diagnosis, assessment and severity and initial antimicrobial therapy. Am Rev Respir Dis 1993; 148: 1418-1426.

7. British Thoracic Society. Guidelines for the management of community-acquired pneumonia in adults admitted to hospital. Br J Hosp Med 1993; 49: 346-350.

8. Mandell LA, Niederman M. The Canadian CommunityAcquired Pneumonia Consensus Group. Antimicrobial treatment of community-acquired pneumonia in adults: a conference report. Can J Infect Dis 1993; 4: 25-28.
9. Dahmash NS, Chowdhury MN. Re-evaluation of pneumonia requiring admission to an intensive care unit: a prospective study. Thorax 1994; 490: 71-76.

10. Lee HK, Hui KP, Tan WC, Lim TK. Severe community acquired pneumonia in Singapore. Singapore Med J 1996; 37: 374-377.

11. Boonsawa W, Boonma P, Tangdajahiran T, Paupermpoonsir S, Wongpratoom W, Romphryk A. Community-acquired pneumonia in adults at Svinagarind Hospital. J Med Assoc Thai 1990; 73: 345-351.

12. Tan AL, Ang BSP, Ong YY. Melioidosis. Epidemiology and antibiogram of cases in Singapore. Singapore Med J 1990; 31: 335-337.

13. Curried B, Howard D, Nguyen VT, Withnall K, Merianos A. The 1990-91 outbreak of meliodosis in the Northern Territory of Australia: clinical aspects. SE Asian J Trop Med Publ Health 1993; 23: 436-443.

14. Suputtamongkol Y. Diagnosis and treatment of meliodosis. Med Prog 1996; 23: 19-22.

15. Rello J, Rodriguez R, Jubert P, Alvarez B. Severe community-acquired pneumonia in the elderly: epidemiology and prognosis. Study group for severe community-acquired pneumonia. Clin Infect Dis 1996; 23: 723-728.

16. Feldman C, Ross SA, Goolam MD, Omar J, Smith C. The etiology of severe community-acquired pneumonia and its impact on initial, empiric, antimicrobial chemotherapy. Respir Med 1995; 89: 187-192.

17. Anstey NM, Currie BJ, Withnall KM. Community-acquired Acinetobacter pneumonia in the Northern Territory of Australia. Clin Infect Dis 1992; 14: 83-91. 